\title{
TREATMENT OF WARTS BY IMMUNOTHERAPY USING PURIFIED PROTEIN DERIVATIVE
}

\author{
Choudhary $D^{1^{*}}$, Piya $S^{1}$
}

\section{Affiliation}

1. Lecturer, Department of Dermatology, Venereology and Leprology, Birat Medical College and Teaching Hospital, Nepal

\section{ARTICLE INFO}

\section{Article History}

Received : 06 June, 2018

Accepted : 14 August, 2018

Published : 31 August, 2018

(C) Authors retain copyright and grant the journal right of first publication with the work simultaneously licensed under Creative Commons Attribution License CC - BY 4.0 that allows others to share the work with an acknowledgment of the work's authorship and initial publication in this journal.

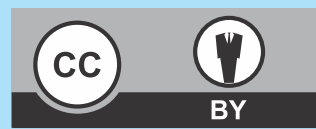

ORA 76

DOI: http://dx.doi.org/10.3126/bjhs.v3i2.20961

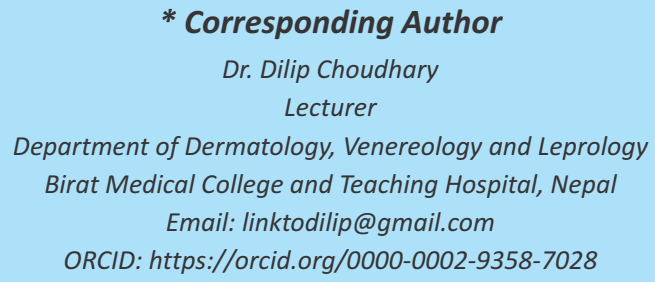

\section{Citation}

Choudhary D., Piya S. Treatment of Warts by Immunotherapy using Purified Protein Derivative. BJHS 2018;3(2)6: 463-467.

\section{ABSTRACT}

\section{Introduction}

Spontaneous clearance of warts has been reported with the development of cell mediated immunity. Various antigens and vaccines have been used for the non specific stimulation of cell mediated immunity and purified protein derivative (PPD) is one of them.

\section{Objective}

To assess the effectiveness of intralesional PPD injection for the clearance of cutaneous warts.

\section{Methodology}

This is an open labeled study and non-probablity sampling method was used for enrolling the cases. Patients with cutaneous warts were injected with PPD intralesionally (2.5 TU) at an interval of 2 weeks for a total of five sessions and they were followed for 6 months after they received the last session therapy.

\section{Results}

A total of 52 patients, 29 males and 23 females, were enrolled in the study and among them 28 patients had verruca vulgaris, 12 patients had verruca plantaris, 9 patients had periungual wart and 3 patients had verruca plana. Total clearance of warts was seen in $78.8 \%(41)$ of patients, however $21.2 \%$ (11) patient did not respond to the therapy. Most of the patients tolerated the therapy well and few of them had mild side effects like erythema, pain and oedema at the site of injection.

\section{Conclusion}

Immunotherapy with intralesional injection of PPD is a safe and effective way to treat cutaneous warts with good response rate.

\section{KEYWORDS}

Immunotherapy, purified protein derivative, warts 


\section{INTRODUCTION}

Infection of keratinocytes by human papilloma virus (HPVs) causes warts in human beings. Because these viruses have tropism for epithelial cells they manifest clinically as mucocutaneous lesions. ${ }^{1}$ Due to their long period of latency in the host cells they are prone to recurrences causing both benign and malignant lesions. Cutaneous warts are the most common manifestation among the benign lesions caused by these viruses. ${ }^{2}$ Though it is a common self limiting dermatological condition, however in some cases they may be persistent and may increase in size and number. A lot of standard modalities are available at present for the treatment of warts and most of them utilize local destruction of virally infected tissues. The locally destructive methods available at present are chemical or electric cauterization, electrofulguration, carbon dioxide laser or cryotherapy. Though the results of these treatments are satisfactory, these modalities are associated with frequent recurrences along with significant scarring and dyspigmentation. Development of cell mediated immune response to the virus is an essential component for clearance of wart and it has shown spontaneous regression of warts. In search for the optimal treatment of warts injection of various immunotherapeutic agents intralesionally have gained popularity in the recent past. ${ }^{3} \mathrm{~A}$ variable response has been observed with the use of Antigens such as the measles, mumps, and rubella (MMR) vaccine; Candida albicans; Bacillus Calmette-Guérin (BCG), and Mycobacterium indicus pranii injected intralesionally. ${ }^{4}$

This study aims at evaluating the efficacy and safety of intralesional Purified protein derivative, ubiquitously used, standardized, easily available, safe and inexpensive antigen, in the treatment of cutaneous warts.

\section{METHODOLOGY}

This open labelled study was conducted in the Department of Dermatology, Venereology and Leprology, Birat Medical college Teaching Hospital, Biratnagar, Nepal from July 1 to December 30, 2017. Patient visiting the outpatient department of Dermatology who presented with wart anywhere in the body were included in the study. Permission for the study was taken from the institution.

A total of 52 patients with different cutaneous viral warts were recruited for the study. All these patients were diagnosed with cutaneous warts and were either untreated or were off the treatment for past 1 month. Patients with active infection or systemic illnesses, those on immunosuppressive drugs, pregnant women and patient not giving consent were not included in the study. Written and informed consent was taken from each patient before starting the treatment and they were fully explained about the disease, including nature course and also about the procedure they were about to undergo, follow up and prognosis. A detailed history and examination was also carried out to determine the number of lesions, types of wart, size and if there was any other associated co-morbid condition. After the patient had met all pre requisite 2.5 TU of PPD was injected into each wart until the lesions got blanched. In cases where patients had numerous lesions the maximum dose of PPD was limited to $25 \mathrm{TU}$ in a single session. Injections were given with similar single use disposable insulin syringes with bevel facing upward and syringe held parallel to the cutaneous surface. All the patients were advised for a total of five sessions each at an interval of 2 weeks. The patients were advised for strict follow up even if they were cleared of the lesions earlier than the 10 weeks period. No further injections were given if the lesions cleared earlier. Examination and evaluation of the patient in terms of regression of lesions was done at every visit. Meanwhile the patients were not allowed to use any other topical or systemic medication in concurrence with the undergoing therapy. All the patients were asked about the recurrence of lesions after a period of 6 months via telephone.

\section{Response to the therapy was scored as}

Responder: Includes patients with complete clearance of lesions

Non Responder: Includes patients with partial or no response to the treatment

\section{RESULT}

A total of 52 patients meeting the inclusion criteria for the study were enrolled in the study. Among the patients included, 29 were males and 23 were females aged between 11 years to 65 years of age. The duration of the existing lesions ranged from 4 months to 48 months. There were different clinical variants of cutaneous warts and among the patients maximum number of patients (28) presented with verruca vulgaris, 12 patients had verruca plantaris, 9 patients had periungual wart and 3 patients had verruca plana. The number of lesions ranged from 2 to more than 10. Among the treated patients $78.8 \%$ of patients had complete resolution of lesions after 5 sessions whereas $21.2 \%$ patients did not show response to the treatment as shown in (Table 1). PPD was well tolerated by all the patients except for few mild side effects. Around 10 patients had mild erythema and oedema at the site of injection which subsided on it's own in about a weeks time, 2 patients complained of pain at the site of injection requiring mild analgesic like NSAIDs and 1 patient developed low grade fever that required antipyretic (Paracetamol). None of the patient complained of scarring or pigmentary changes at the site that were resolved of warts and there was no recurrence in any of the patients after a follow up of 6 months.

\begin{tabular}{lcc}
$\begin{array}{l}\text { Table 1: Frequency of responders } \\
\text { Frequency }\end{array}$ & Percentage \\
\hline Responder & 41 & 78.8 \\
Non responder & 11 & 21.2
\end{tabular}


Table 2: Frequency of responders

\section{Frequency}

Percentage

Responder

41

78.8

Non responder

11

21.2

Table 3 : Clearance rates in various types of warts

\begin{tabular}{|l|c|c|c|}
\hline \multicolumn{1}{|c|}{ Type } & $\begin{array}{c}\text { Number of } \\
\text { patients }\end{array}$ & Responder & $\begin{array}{c}\text { Non } \\
\text { responder }\end{array}$ \\
\hline Vulgaris & 28 & 24 & 4 \\
\hline Plantar & 12 & 7 & 5 \\
\hline Verruca plana & 3 & 3 & 0 \\
\hline Periungual & 9 & 7 & 2 \\
\hline
\end{tabular}

Table 3: Response rate according to number of sessions

\begin{tabular}{|c|c|c|}
\hline $\begin{array}{c}\text { Number of } \\
\text { sessions }\end{array}$ & $\begin{array}{c}\text { No. of } \\
\text { responded } \\
\text { patients }\end{array}$ & $\begin{array}{c}\text { Cumulative } \\
\text { response(\%) }\end{array}$ \\
\hline 1 & 3 & 7.31 \\
\hline 2 & 15 & 36.58 \\
\hline 3 & 13 & 31.70 \\
\hline 4 & 10 & 24.39 \\
\hline 5 & 0 & 0 \\
\hline
\end{tabular}

treatment, a number of different modalities are available but all of them aim at local destruction of tissue causing significant scarring and pigmentary changes. ${ }^{5}$ Treatment with immunotherapy has shown regression of warts that too without any pigmentation or scarring. ${ }^{6}$ Added benefit in comparison to destructive therapy is minimal recurrence of the lesion after it's regression. ${ }^{5}$ The role of immunity has been well proven by the fact that there is increased incidence of warts in immunocompromised subjects and spontaneous clearance of lesions with the enhanced immunity. ${ }^{7}$ The protective function of cell mediated immunity against fungal viral and mycobacterial infection is a well known fact and hence fungal, viral, mycobacterial antigens along with vaccines have been in use for stimulation of cell mediated immunity. ${ }^{8,9}$ Since prevalence of tuberculosis is on a higher side in Nepal we choose to use PPD as immunostimulant because of ease in inducing a positive cell mediated immune response to PPD and also because of its easy availability.

The effectiveness for clearance of wart by PPD is due to nonspecific stimulation of cell mediated immunity through activation of Th1 cytokines, natural killer cells and cytotoxic T cells. ${ }^{10}$ In a few studies it has been shown that there is significantly Increased rate of clearance of warts with PPD injection when compared with injection of normal saline

Table 4: Response rates to various antigens and vaccines

\begin{tabular}{|l|l|c|c|c|}
\hline \multicolumn{1}{|c|}{ Study } & \multicolumn{1}{|c|}{ Antigen/vaccine } & $\begin{array}{c}\text { No. of } \\
\text { sessions given }\end{array}$ & $\begin{array}{c}\text { Duration between } \\
\text { two sessions(weeks) }\end{array}$ & $\begin{array}{c}\text { Clearance } \\
\text { rate (\%) }\end{array}$ \\
\hline Wanankul et al & PPD & 6 & 2 & 93 \\
\hline Eassa et al $^{10}$ & PPD & 12 & 1 & 47 \\
\hline Nofal and Nofal $^{8}$ & MMR vaccine & 5 & 2 & 85 \\
\hline Johnson et al $^{9}$ & Mumps or candida & 3 & 3 & 74 \\
\hline Gupta et al & & & 1 & 89 \\
\hline Present study & Mycobacterium vaccine & 10 & 1 & 78.8 \\
\hline
\end{tabular}

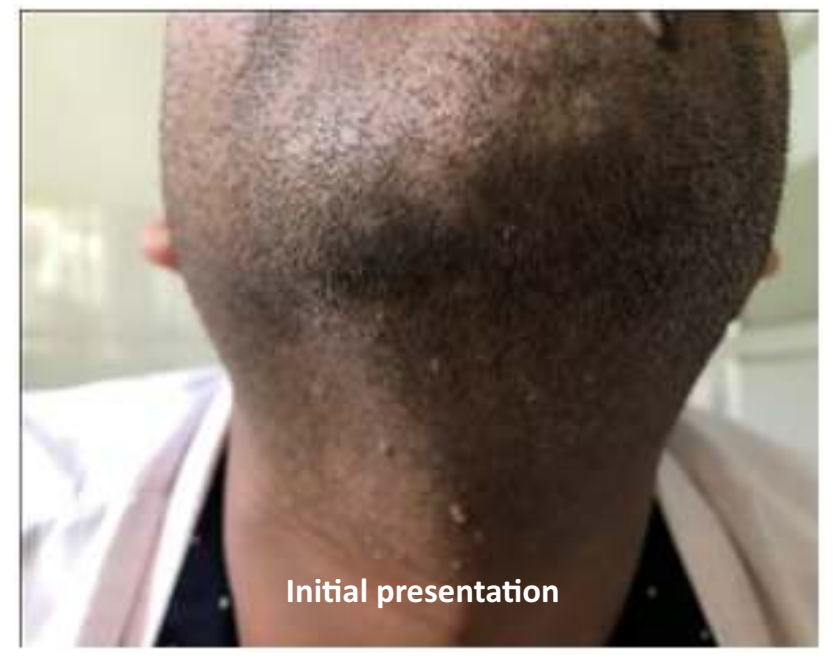

\section{DISCUSSION}

Cutaneous warts are caused by infection of keratinocytes by human papilloma virus and is one of the frequently encountered disease in dermatology OPD.As for

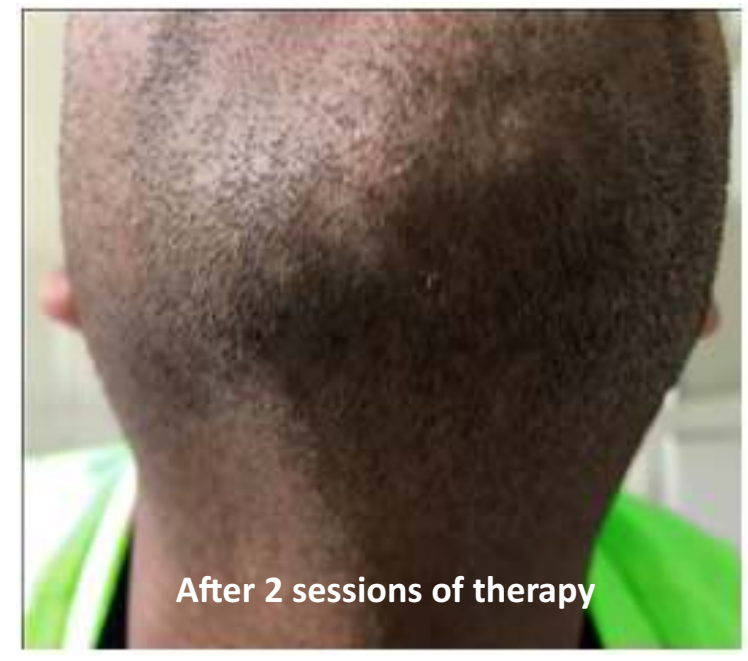

thus signifying the fact that clearance of wart is due to immunity stimulation rather than due to effect of injection alone. ${ }^{8,11}$ It has also been proved that PPD injection not only stimulates the local immunity but also causes activated $T$ 


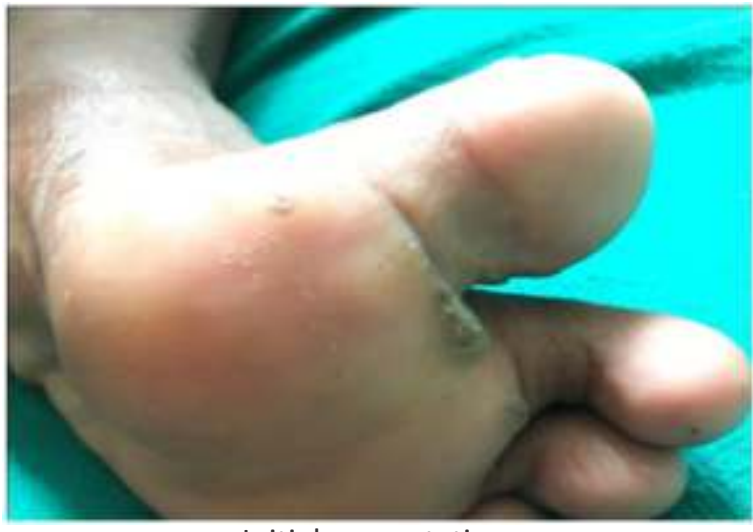

Initial presentation

cells to circulate all over the body and helps in clearance of the distant non injected warts as well. ${ }^{10}$

Use of PPD has been proven to be safe among the children and pregnant women as well because of the fact that PPD does not contain any viable organisms. A study done by Essa et al has shown a high success rate for clearance of ano-genital warts without any significant side effects in pregnant women with use of PPD. ${ }^{10}$ Hypersensitivity is a very rare occurrence that can take place in $1 /$ million case. ${ }^{12}$ There is no linear correlation between skin reaction and tuberculin dose and maximum dose of PPD used has been documented to be 88 TU till date..$^{13}$ In our study we used a maximum dose of $20 \mathrm{TU}$ in one patient who developed flu like symptoms that was easily managed with NSAIDs. There is no standard protocol regarding the dose, interval between injections, number of sessions and different studies show variation in these things as shown in table 4. However as we know that the time for induration to heal in montuex test takes around 7-12 days we decided to keep the interval of 2 weeks between the subsequent injections. Table 4 shows in brief the response rate of different antigens used for eradication of warts. Our study shows that $78.8 \%$ of patients were cleared of warts in 5 sessions which is quite significant. This study along with several other studies shows that whenever intra-lesional injections were given at multiple sites and in multiple sessions there was greater chance of faster and effective clearance of warts. ${ }^{8,10,11,14}$ Tuberculin jelly as a topical immunotherapy has also been used in this context but a very lower response rate $57 \%$ and hence it is more appropriate that the route of administration be intralesional for better results. ${ }^{15}$

The patients in our study tolerated PPD injection very well except for few developing very mild side effects like pain, erythema and oedema at injection site and none of the patient had recurrence after a period of 6 months.

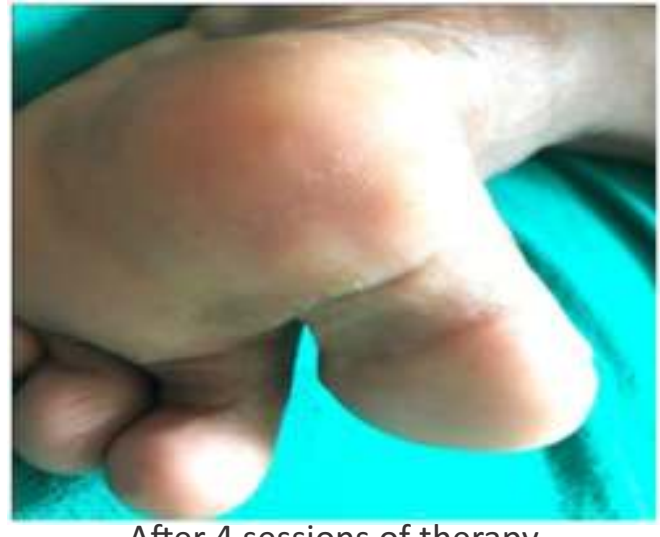

After 4 sessions of therapy

\section{CONCLUSION}

Though at present a variety of options of therapy are available for the treatment of cutaneous warts, all of them acts in the principal of destruction of local tissue which may lead to significant scarring. In this era where patients are very much concerned about the cosmetic appearance these destructive methods may not be appropriate and hence an alternative therapy to avoid those consequences is required. As suggested by our study immunotherapy using intralesional injection of PPD may serve as a good alternative for the treatment of warts without any significant side effects even in pregnant woman and pediatric age group. Also cheaper cost and easy availability of PPD makes it a very good treatment option.

\section{RECOMMENDATIONS}

Further similar larger scale comparative studies are required to further validate the efficacy of intralesional PPD injections for the treatment of cutaneous warts.

\section{LIMITATIONS OF THE STUDY}

The limitation of our study was a small sample size and absence of control group. Also could not perform montoux test in all the subjects because of technical problems and hence we could not find the correlation between montoux positivity and clearance rate of warts.

\section{ACKNOWLEDGEMENT}

The author would like to thank all the patients who gave the opportunity to conduct the study.

\section{CONFLICT OF INTEREST}

None

\section{FINANCIALDISCLOSURE}

None

\section{REFERENCES}

1. Leto M, Santos Junior GF, Porro AM, Tomimori J. Human papillomavirus infection: etiopathogenesis, molecular biology and clinical manifestations. Anais brasileiros de dermatologia. 2011;86(2):306-17.PMID :21603814

2. Antonsson A, Forslund O, Ekberg H, Sterner G, Hansson BG. The ubiquity and impressive genomic diversity of human skin papillomaviruses suggest a commensalic nature of these viruses. Journal of virology. 2000;74(24):11636-41.PMID :11090162 
3. Lipke MM. An armamentarium of wart treatments. Clinical medicine \& research. 2006;4(4):273-93. PMID: 17210977

4. Awal G, Kaur S. Therapeutic Outcome of Intralesional Immunotherapy in Cutaneous Warts Using the Mumps, Measles, and Rubella Vaccine: A Randomized, Placebo-controlled Trial. The Journal of clinical and aesthetic dermatology. 2018;11(5):1520.PMID: 29785233

5. Sterling JC, Handfield-Jones S, Hudson PM. Guidelines for the management of cutaneous warts. The British journal of dermatology. 2001;144(1):4-11. PMID: 11167676

6. Clifton MM, Johnson SM, Roberson PK, Kincannon J, Horn TD. Immunotherapy for recalcitrant warts in children using intralesional mumps or Candida antigens. Pediatric dermatology. 2003;20(3):26871. PMID : 12787281

7. Majewski S, Jablonska S. Immunology of HPV infection and HPVassociated tumors. International journal of dermatology. 1998;37(2): 81-95. PMID: 9542660

8. Nofal A, Nofal E. Intralesional immunotherapy of common warts: successful treatment with mumps, measles and rubella vaccine. Journal of the European Academy of Dermatology and Venereology: JEADV. 2010;24(10):1166-70. PMID:20202055

9. Johnson SM, Roberson PK, Horn TD. Intralesional injection of mumps or Candida skin test antigens: a novel immunotherapy for warts. Archives of dermatology. 2001;137(4):451-5.PMID:11295925
10. Eassa BI, Abou-Bakr AA, El-Khalawany MA. Intradermal injection of PPD as a novel approach of immunotherapy in anogenital warts in pregnant women. Dermatologic therapy. 2011;24(1):137-43.PMID: 21276168

11. Horn TD, Johnson SM, Helm RM, Roberson PK. Intralesional immunotherapy of warts with mumps, Candida, and Trichophyton skin test antigens: a single-blinded, randomized, and controlled trial. Archives of dermatology. 2005;141(5):589-94.PMID: 15897380

12. Froeschle JE, Ruben FL, Bloh AM. Immediate hypersensitivity reactions after use of tuberculin skin testing. Clinical infectious diseases : an official publication of the Infectious Diseases Society of America. 2002;34(1):E12-3.PMID: 11731966

13. Dimoliatis ID, Liaskos CA. Six Mantoux tuberculin skin tests with 1, 2, $5,10,20$, and 50 units in a healthy male without side-effects - is skin reaction a linear function of tuberculin dose? Cases journal. 2008;1(1):115.PMID: 18715513

14. Gupta S, Malhotra AK, Verma KK, Sharma VK. Intralesional immunotherapy with killed Mycobacterium $w$ vaccine for the treatment of ano-genital warts: an open label pilot study. Journal of the European Academy of Dermatology and Venereology : JEADV. 2008;22(9):1089-93.PMID:18484970

15. Lahti A, Hannuksela M. Topical immunotherapy with tuberculin jelly for common warts. Archives of dermatological research. 1982;273 (1-2): 153-4.PMID:7184471

16 Wananukul S, Chatproedprai S, Kittiratsacha P. Intralesional immunotherapy using tuberculin PPD in the treatment of palmoplantar and periungual warts. Asian Biomed 2009;3:739-43. 